\title{
Oocyte-specific inactivation of Omcg1 leads to DNA damage and c-Abl/TAp63-dependent oocyte death associated with dramatic remodeling of ovarian somatic cells
}

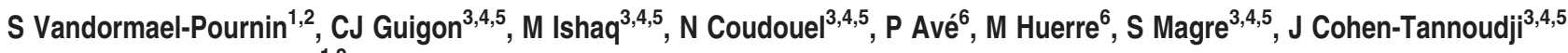 \\ and M Cohen-Tannoudji ${ }^{\star, 1,2}$
}

\begin{abstract}
Aberrant loss of oocytes following cancer treatments or genetic mutations leads to premature ovarian insufficiency (POI) associated with endocrine-related disorders in $1 \%$ of women. Therefore, understanding the mechanisms governing oocyte death is crucial for the preservation of female fertility. Here, we report the striking reproductive features of a novel mouse model of POI obtained through oocyte-specific inactivation (ocKO) of Omcg1/Zfp830 encoding a nuclear zinc finger protein involved in premRNA processing. Genetic ablation of OMCG1 in early growing oocytes leads to reduced transcription, accumulation of DNA double-strand breaks and subsequent C-AbI/TAp63-dependent oocyte death, thus uncovering the key role of OMCG1 for oocyte genomic integrity. All adult Omcg $1^{\text {ocKO }}$ females displayed complete elimination of early growing oocytes and sterility. Unexpectedly, mutant females exhibited a normal onset of puberty and sexual receptivity. Detailed studies of Omcg $1^{\text {ocKO }}$ ovaries revealed that the ovarian somatic compartment underwent a dramatic structural and functional remodeling. This allowed the cooperation between oocyte-depleted follicles and interstitial tissue to produce estradiol. Moreover, despite early folliculogenesis arrest, mutant mice exhibited sexual cyclicity as shown by cyclical changes in estrogen secretion, vaginal epithelium cytology and genital tract weight. Collectively, our findings demonstrate the key role of Omcg1 for oocyte survival and highlight the contribution of p63 pathway in damaged oocyte elimination in adulthood. Moreover, our findings challenge the prevailing view that sexual cyclicity is tightly dependent upon the pace of folliculogenesis and luteal differentiation.
\end{abstract}

Cell Death and Differentiation (2015) 22, 108-117; doi:10.1038/cdd.2014.122; published online 29 August 2014

Differentiation and release of mature oocytes are crucial for the successful propagation of species. Female fertility depends on the availability of ovarian follicles, which are hormone-producing structures nursing the oocytes. At each reproductive cycle, ovarian folliculogenesis leads to the terminal maturation of follicles for ovulation. Ovarian insufficiency, whether age-related or induced by pathologies, is frequently driven by depletion of oocytes. As a consequence, dramatic changes in the endocrine activity of the ovary ensue, associated with an array of health complications. ${ }^{1}$ Understanding the mechanisms underlying oocyte death is therefore a major issue of reproductive and endocrinological sciences. Although in most cases ovarian failure is of idiopathic origin, cancer treatments and genetic mutations are known inducers. ${ }^{2}$ However, so far, and contrasting with somatic cells, little is known about the mechanisms regulating oocyte death.

Oocytes are arrested in prophase of the first meiotic division. During folliculogenesis, oocyte growth is accompanied by a dramatic increase in gene transcription, a necessary step for the storage of proteins ensuring oocyte growth and dialogue with companion granulosa cells in addition to fertilization and embryo development. ${ }^{3,4}$ Limited data are available concerning the transcriptional machinery and its regulation during oocyte growth. ${ }^{5}$ Ovum mutant candidate gene 1 (Omcg1), also known as Ccdc16 and Zfp830, encodes a nuclear zinc finger protein involved in pre-mRNA processing including splicing ${ }^{6}$ and transcription-coupled repair. ${ }^{7}$ In the absence of OMCG1, conflicts between defective pre-mRNA processing and replication generate DNA damage accrual leading to dramatic genomic instabilities and elimination of cycling cells. $^{8,9}$

To determine whether OMCG1 could also play a role in the meiotic female germ cell, we analyzed genetically engineered mice, named thereafter Omcg $1^{\text {OcKO }}$ mice, harboring Omcg 1 inactivation specifically in oocytes at the onset of their growing phase. Omcg1 disruption led to an overall reduction in transcription, accumulation of DNA strand breaks (DSB) and

${ }^{1}$ Institut Pasteur, Unité de Génétique Fonctionnelle de la Souris, Département de Biologie du Développement et Cellules Souches, 25 rue du docteur Roux, Paris F-75015, France; ${ }^{2}$ CNRS URA 2578, Paris F-75015, France; ${ }^{3}$ INSERM U1133, Physiologie de l'Axe Gonadotrope, Paris F-75013, France; ${ }^{4}$ Université Paris Diderot, Sorbonne Paris Cité, Paris F-75013, France; ${ }^{5}$ CNRS, UMR 8251, Biologie Fonctionnelle et Adaptative, Paris F-75013, France and ${ }^{6}$ Institut Pasteur, Unité de Recherche et d'Expertise Histotechnologie et Pathologie, Paris F-75015, France

*Corresponding author: M Cohen-Tannoudji, Unité de Génétique Fonctionnelle de la Souris, Département de Biologie du Développement, 25 rue du docteur Roux, Paris F-75015, France. Tel: +33 1456884 86; Fax: +33 1456886 34; E-mail: m-cohen@ pasteur.fr

Abbreviations: DSB, DNA strand breaks; ocKO, oocyte-specific inactivation; Omcg1, Ovum mutant candidate gene 1; Pol II, RNA Polymerase II; POI, premature ovarian insufficiency

Received 11.4.14; revised 11.7.14; accepted 13.7.14; Edited by JC Marine; published online 29.8.14 
eventually transactivating (TA) p63-dependent death of oocytes at the primary follicle stage. As a result of growing oocyte depletion, Omcg $1^{\text {ocKO }}$ mice displayed premature ovarian insufficiency (POI) and sterility. Strikingly, despite the absence of terminal folliculogenesis, mutant females exhibited patterns of estrous cyclicity, estrous-related changes in estradiol production and sexual receptivity. This was associated with the profound remodeling of ovarian somatic compartment, displaying differentiation of estradiolproducing cells. Besides uncovering the key role of OMCG1dependent pre-mRNA processing, our study challenges, in the case of $\mathrm{POI}$, the current dogma whereby sexual cyclicity is tightly dependent upon oocyte endowment and pace of folliculogenesis.

\section{Results}

Conditional inactivation of Omcg1 in oocytes leads to oocyte loss at the beginning of follicular growth. OMCG1 is present in ovulated oocyte, ${ }^{10}$ but its expression profile during folliculogenesis was not known. Immunostaining of OMCG1 revealed its expression in the nuclei of oocytes from primordial to antral follicles and in granulosa cells from early preantral stage onwards (Supplementary Figure S1). To address the function of OMCG1 during oocyte growth, we performed Omcg1 conditional inactivation using the ZP3-cre transgenic strain. ${ }^{11}$ We set up crosses allowing the production within the same litter of both mutant (Omcg $1^{\text {flox } / d e l}$; ZP3-Cre $e^{\text {tg/g }}$ ) and control $\left(O m c g 1^{\text {flox } /+}\right.$;
ZP3-Cre ${ }^{t g / 9}$ females (Supplementary Figure S2). Both types of females also carried the $R 26 R$ reporter $^{12}$ to label oocytes having experienced Cre recombination. Importantly, Cre expression was restricted to oocytes, and Omcg $1^{\text {flox }}$ to Omcg $1^{\text {del }}$ allele conversion was effective shortly after primordial oocyte activation (Supplementary Figure S2).

Mating of Omcg $1^{\text {ockO }}$ females with wild-type males over a 10-month period failed to produce any offspring (Figure 1a). Mutant females had small ovaries compared with control littermates (Figures $1 \mathrm{~b}$ and $\mathrm{c}$ ). In control ovaries, follicles from the primordial to the preovulatory stage and corpora lutea were observed (Figure 1c). In contrast, mutant ovaries contained primordial follicles and early growing follicles at the primary follicular stage, but lacked more advanced follicles and corpora lutea. Histomorphometric analysis revealed that mutant ovaries contained similar numbers of primordial and primary follicles compared with controls but were totally devoid of follicles beyond the preantral stage (Table 1). Omcg $1^{\text {ockO }}$ ovaries contained a well-developed interstitial tissue in their central part and numerous follicular-like structures in the cortical region (Figure 1d). Enlarged magnification revealed that these structures were primordial and primary follicles as well as oocyte-depleted follicles, indicating that Omcg1-deficient oocytes were lost rapidly after the initiation of folliculogenesis (Figures 1d-i). Oocytes from late primary follicles of mutant ovaries displayed obvious signs of degeneration such as chromatin condensation and cytoplasmic vacuolization (Figures $1 \mathrm{~h}-\mathrm{i}$ ), but no cleaved Caspase-3 immunostaining (Supplementary Figure S3) a
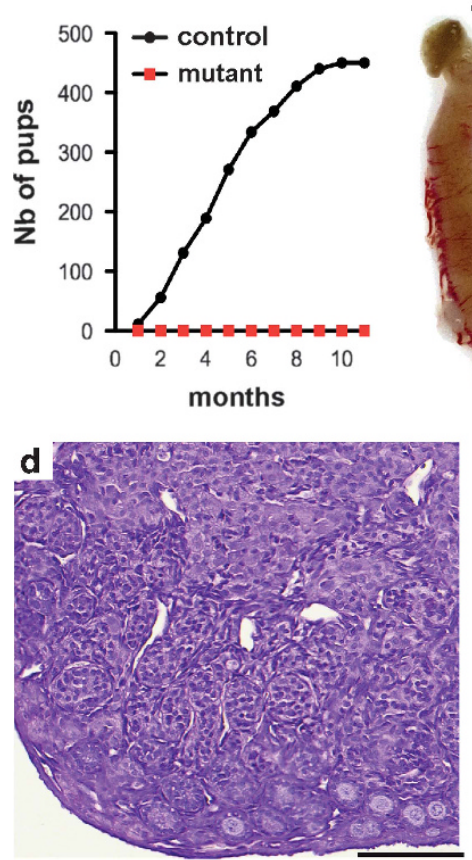

b
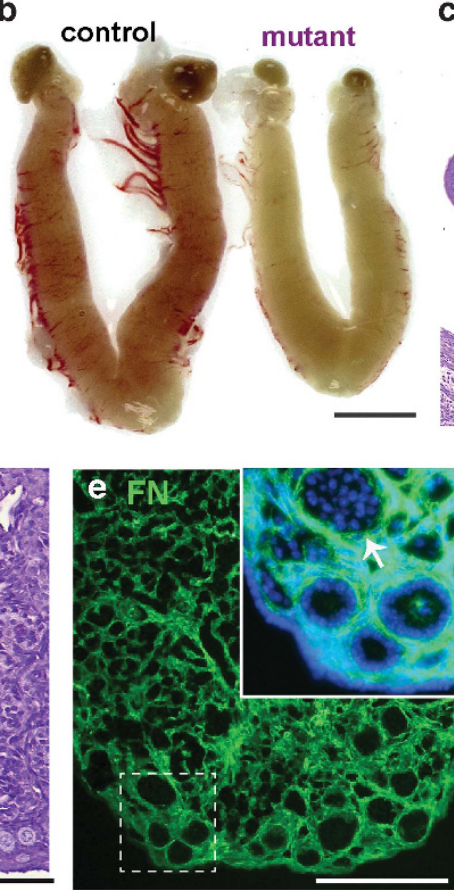

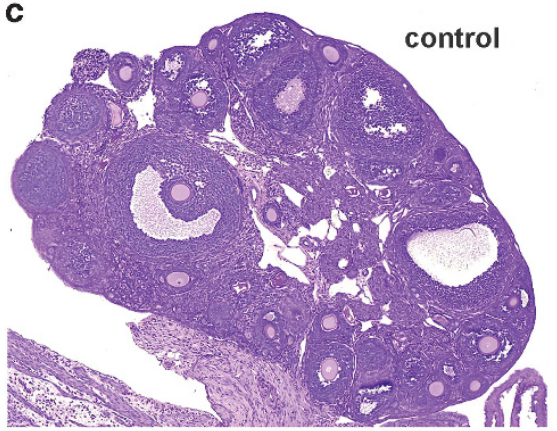

mutant

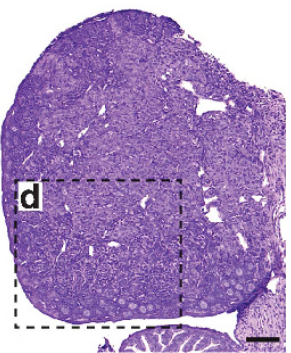

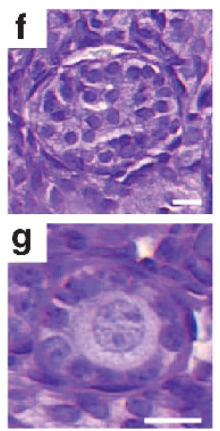
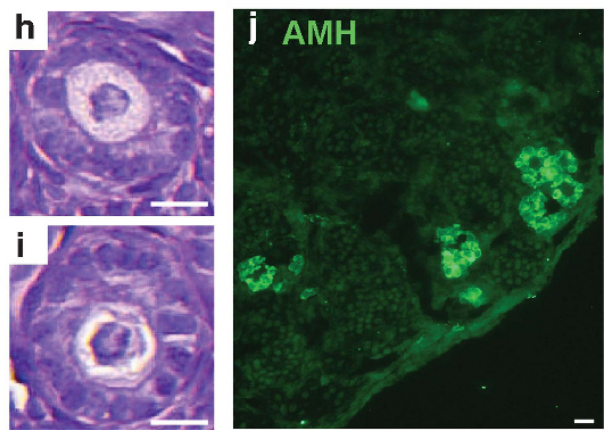

Figure 1 Sterility and early folliculogenesis arrest in Omcg $1^{\text {ockO }}$ females. (a) Cumulative number of progenies (five mice per genotype). (b) Gross morphology of genital organs. (c) Histological analysis of control and mutant ovaries. (d) Enlarged magnification of the mutant ovary depicting the lack of growing follicles beyond the primary stage. (e) Immunofluorescence staining of fibronectin (FN) and double staining by Hoechst (inset) revealing the presence of primary follicles and one oocyte-depleted follicle (arrow). (f-i) Higher magnification showing an oocyte-depleted follicle (f), a healthy primary follicle (g) and primary follicles exhibiting signs of oocyte degeneration (h, i). (j) AMH immunofluorescence staining in a mutant ovary to detect healthy growing follicles. Only follicles harboring one layer of granulosa cells, which correspond to primary follicles, express AMH. (Scale bars: b, $5 \mathrm{~mm} ; \mathbf{c}-\mathbf{e}, 200 \mu \mathrm{m} ; \mathbf{f}-\mathbf{j}, 20 \mu \mathrm{m}$ ) 
suggesting their rapid elimination and/or the involvement of alternative cell death mechanisms, as already suggested for physiological oocyte death. ${ }^{13}$ Arrest of folliculogenesis beyond the primary stage was confirmed by in situ study of anti-Müllerian hormone (AMH), a marker of healthy growing follicles that was only detected in one-layer primary follicles (Figure 1j). Somatic cell apoptosis was minimal in oocytedepleted follicles (Supplementary Figures S3 and S4), further illustrating that granulosa cells survived despite oocyte loss. Altogether, our data show that Omcg $1^{\text {ocKO }}$ mice constitute a novel model of POI resulting from the loss of early growing oocytes.

Table 1 Histomorphometric analyses of control and mutant ovaries

\begin{tabular}{|lccc|}
\hline Follicular stage & Control $(\boldsymbol{n}=\mathbf{3})$ & Mutant $(\boldsymbol{n}=\mathbf{7})$ & $\boldsymbol{P}$ \\
\hline Primordial & $378.0 \pm 31$ & $492.4 \pm 36.1$ & 0.093 \\
Primary & $76.3 \pm 5.8$ & $50.1 \pm 8.3$ & 0.091 \\
Preantral & $61.7 \pm 6.4$ & 0 & $<0.01$ \\
\hline
\end{tabular}
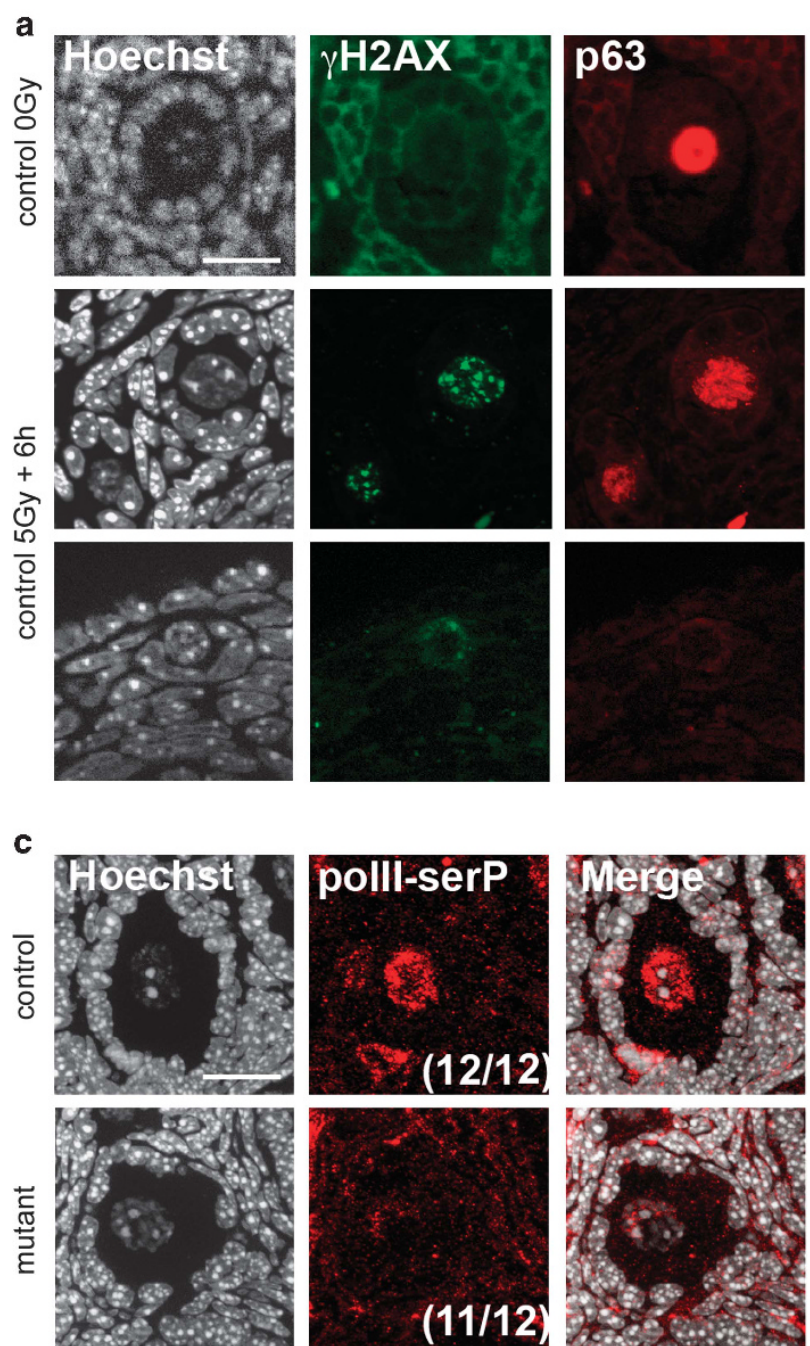

DNA breaks and reduced transcription precede the elimination of Omcg1-deficient oocytes. Because OMCG1 was shown to participate in genome integrity, ${ }^{8-10}$ we monitored DNA damage in Omcg $1^{\text {ocKO }}$ oocytes before their elimination. Under normal conditions, growing oocytes from control adult females were devoid of phosphorylated form of $\mathrm{H} 2 \mathrm{AX}(\gamma \mathrm{H} 2 \mathrm{AX})$ staining, an early marker of DNA damage response. However, they showed numerous nuclear foci of $\gamma \mathrm{H} 2 \mathrm{AX}$ staining after exposure to whole-body $\gamma$-irradiation (Figure 2a). In mutant females, oocytes from late primary follicles exhibited high levels of $\gamma \mathrm{H} 2 \mathrm{AX}$ staining (Figure $2 b$ ) indicating that OMCG1 loss rapidly causes DSB in oocyte. TAp63 $\alpha$, the main p63 isoform expressed in oocyte, is critical for the elimination of primordial oocytes in immature ovaries after DNA damage in vivo. ${ }^{14-16}$ In line with previous studies, ${ }^{14,17}$ we observed a strong nuclear TAp63 expression in oocytes from primordial to early antral follicles in control adult ovaries (Figures $2 a$ and b). In contrast, a majority of large primary oocytes showed a reduced or absent TAp63 staining in adult Omcg1 ${ }^{\text {ocKO }}$ females (Figure $2 b$ ). b
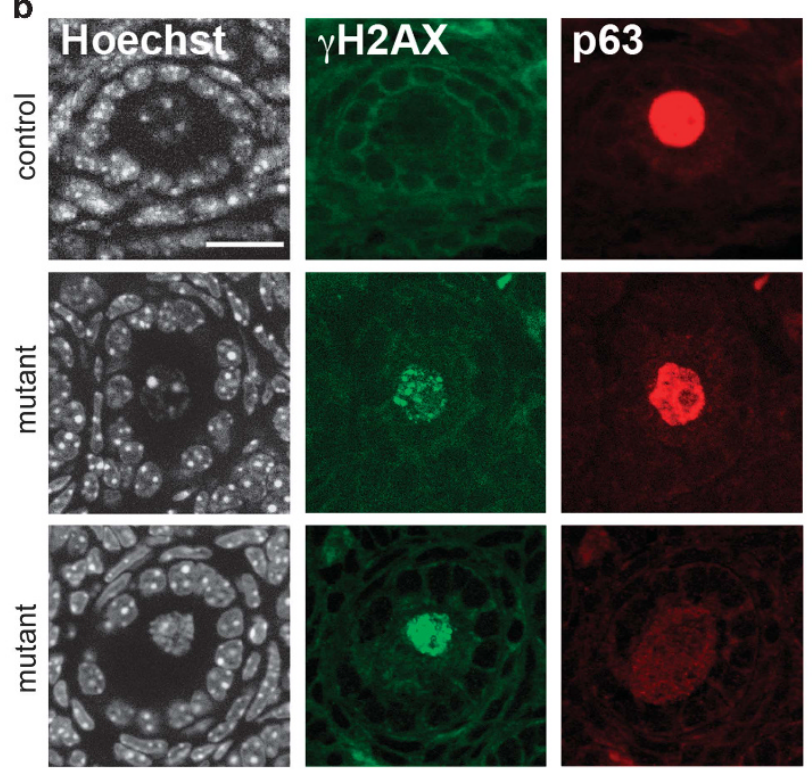

d
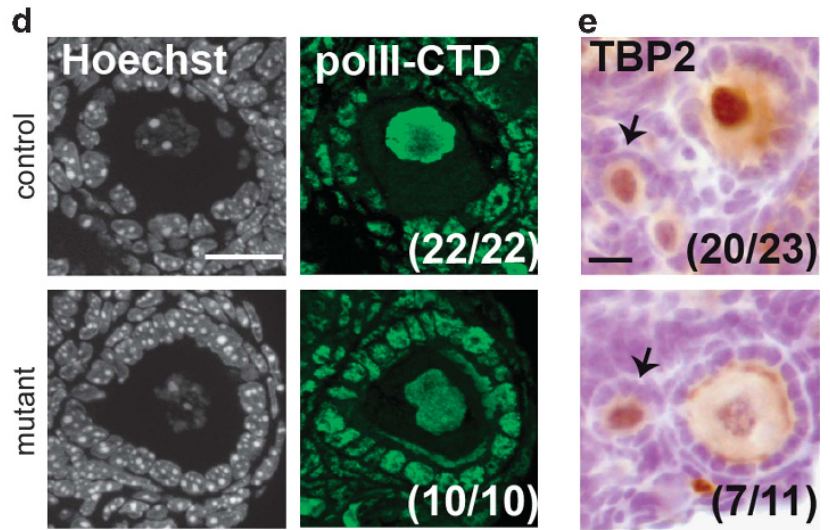

Figure 2 DNA damage and decreased transcriptional activity in Omcg $1^{\text {ocKO }}$ oocytes. (a, b) Immunofluorescence analysis with anti- $\gamma \mathrm{H} 2 \mathrm{AX}$ and anti-TAp63 antibodies of oocytes from adult untreated and irradiated control as well as untreated mutant females. (c-e) Immunodetection analysis of control and Omcg ${ }^{1}{ }^{\circ K O}$ ovarian sections from P10 females using antibodies recognizing the Ser2/5-phophorylated CTD of Pol II (C), all forms of the CTD of Pol II (d) and TBP2 (e). Arrows point to activated primordial follicles. (Scale bars: $20 \mu \mathrm{m}$ ) 
Decreased TAp63 staining was also observed in control oocytes from primordial and primary follicles following irradiation (Figure 2a). Downregulation of TAp63 in damaged oocytes has been previously observed ${ }^{14,18}$ and likely reflects its activation following DNA damage-induced phosphorylation. Indeed, phosphorylation not only induces a conformational switch ${ }^{19}$ that activates TAp63 leading to the transcriptional induction of proapoptic genes ${ }^{18}$ but also increases its susceptibility to degradation. ${ }^{14,19}$

OMCG1 is involved in co-transcriptional processes. ${ }^{6-8} \mathrm{We}$, thus, examined transcriptional activity in Omcg $1^{\text {ocKO }}$ primary oocytes. Consistent with a previous report, ${ }^{20}$ we could detect significant levels of RNA Polymerase II (Pol II) elongation, using an antibody recognizing specific phospho-epitopes of Pol II, in all the observed control primary oocytes $(n=12 / 12)$ (Figure $2 c)$. In contrast, most mutant primary oocytes $(n=11 / 12)$ were lacking such staining although all displayed normal levels of total Pol II protein (Figures 2c and d). Immunodetection of TBP2, an oocyte-specific TATA-Box protein factor critical for transcriptional activity during oocyte growth, ${ }^{20}$ revealed that contrary to controls, most Omcg $1^{\text {ocKO }}$ primary oocytes did not stain for TBP2 (Figure 2e). In contrast, at earlier folliculogenesis stages, that is, before (primordial) and shortly (primordial to primary) after Omcg1 inactivation, similar TBP2 levels were observed in control and mutant oocytes (Figure 2e, arrows). Taken together, our data suggest that loss of Omcg1 in early growing oocytes causes chromosomal breaks, activation of TAp63 and dramatic downregulation of transcription.

RTK inhibition with imatinib prevents p63 downregulation and developmental arrest of Omcg1-deficient oocytes. We reasoned that DNA damage caused by Omcg1 deficiency might trigger TAp63 activation, leading to the rapid elimination of mutant oocytes. Indeed, when TAp63 is absent or in conditions where its activation by $c-A b l$ kinase is inhibited, oocytes from primordial and early growing follicles are protected from genotoxic stress-induced death in fetal and infantile ovaries. ${ }^{14-16}$ To test our hypothesis, we decided to introgress the Omcg $1^{\text {ocKO }}$ mutation into a TAp63-deficient background. Unfortunately, most TAp63 ${ }^{-1-}$ individuals died in utero or shortly after birth, the remaining being subfertile (Supplementary Figure S5), thereby preventing us to genetically assess the contribution of TAp63 to the Omcg $1^{\text {ockO }}$ phenotype. As an alternative, we used imatinib to inhibit c-Abl tyrosine kinase activity and prevent TAp63 activation. Female mice (7-8-week old) were injected with repeated doses of imatinib $(30 \mathrm{mg} / \mathrm{kg})$ and analyzed $43-45 \mathrm{~h}$ after the first injection (Figure 3a). Impact on oocyte survival was verified in controls by whole-body $\gamma$-irradiation exposure (low dose of $0.5 \mathrm{~Gy}$ ) and X-gal staining of ovaries isolated 24-26h later. As expected, irradiation of untreated control females resulted in a severe and specific loss of small oocytes (Figures $3 b$ and $c$ and Supplementary Figure S6A). In contrast, imatinib treatment provided partial protection to primordial and early growing oocytes in adult ovaries (Figure 3d and Supplementary Figure S6A). Persistence of TAp63 protein in irradiated oocytes (Supplementary Figure S6B) suggests that efficient inhibition of the c-Abl/TAp63 pathway was achieved by the imatinib injection regimen.
We then assayed the consequences of imatinib treatment on the phenotype of Omcg $1^{\text {ocKO }}$ oocytes. X-gal staining of mutant ovaries revealed an increase in the number of early growing oocytes upon imatinib treatment (Figures $3 e$ and f). Quantification of blue oocytes confirmed a $60 \%$ increase in their total number $(77 \pm 2$ in untreated $(n=3)$ versus $122.7 \pm 15.6$ in imatinib-treated $(n=3)$ mutant ovaries; $P<0.05)$, suggesting that this treatment prevented oocyte death. Of note, oocytes larger than those in untreated mutant females were observed (arrows on Figure $3 f$ ). Histological examination revealed the presence of follicles reaching the preantral follicle stage in imatinib mutant ovaries, surrounded by a layer of theca cells (Figure $3 \mathrm{~g}$ ). Remarkably, oocyte nuclei contained high levels of both $\gamma \mathrm{H} 2 \mathrm{AX}$ and TAp63 staining (Figure $3 \mathrm{~g}$ ). Altogether, these data indicate that imatinib treatment prevented TAp63 activation and progression to cell death despite the presence of chromosome breaks in Omcg $1^{\text {ockO }}$ oocytes, thereby allowing folliculogenesis to proceed beyond the primary follicular stage.

Omcg1ocKO mice display sexual cyclicity. Although being infertile, assessment of vaginal opening in mutant females indicated that surprisingly they exhibited normal puberty onset (Figure 4a). Furthermore, adult mutant females still displayed sexual receptivity as evidenced by the occurrence of copulatory plugs when mated with wildtype males (Figure 4b). This, together with the observation of well-developed uteri (Figure 1b), suggests that, unexpectedly, estrogenic stimulation occurred in mutant females. To define the consequences of Omcg1 deletion-induced oocyte loss on reproductive endocrinology, ovarian and pituitary reproductive hormones were analyzed in adult females. Serum levels of inhibin B, which is produced by the granulosa cells of growing follicles, ${ }^{21}$ were totally suppressed in mutant mice (Figure 4c). Consistently, serum levels of the pituitary gonadotropin $\mathrm{FSH}$ were dramatically increased, as were also serum LH concentrations (Figure 4c). A significant rise in the transcript levels of gonadotropin beta subunits was also detected by real-time RT-PCR (Figure 4c). However, surprisingly, serum levels of $17 \beta$-estradiol and testosterone were similar in control and mutant mice (Figure 4c). Observation of vaginal cytology showed the presence of all stages of the estrous cycle in both groups. Daily analysis of vaginal smears over three consecutive weeks (illustrated for three mutant and three control females in Figure 4d) revealed that mutant females displayed patterns of estrous cyclicity. Cycle length (4.35 \pm 0.17 in control $(n=19)$ versus $5.35 \pm 0.5$ days in mutant $(n=21)$ mice, $P>0.05)$ and percentage of time in proestrus/estrus $(31 \pm 2.4$ in control $(n=29)$ versus $35 \pm 2.3 \%$ in mutant $(n=46)$ mice, $P>0.05)$ were similar. Strikingly, the relationship between vaginal cell composition and estradiol secretion ${ }^{22}$ was maintained in mutant females, because serum estradiol levels reached maximal values at the proestrus stage, as observed in controls (Figure 4e). Furthermore, genital tract weights also showed estrousrelated changes, being significantly increased at estrus (Figure 4f). Castration abrogated vaginal cyclicity in mutant females as shown by persistent diestrus ( $n=8 / 9$ mice), indicating that the ovary is responsible for the observed cycle-related changes. Taken together, these data show that 

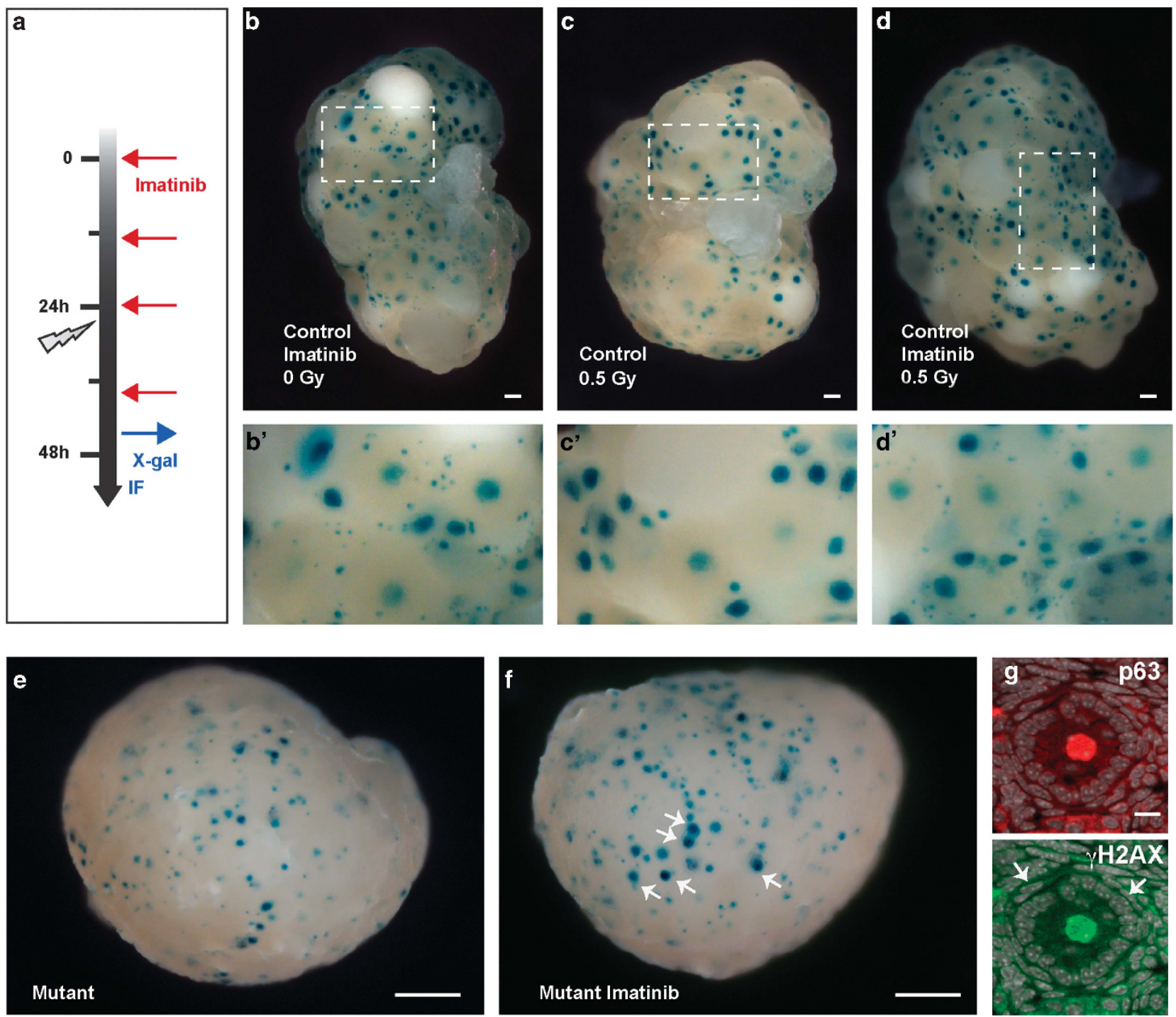

Figure 3 Imatinib treatment promotes survival of damaged Omcg $1^{\text {ocko }}$ oocytes and extended follicular differentiation. (a) Scheme of imatinib injection experimental procedure. (b-f) Whole-mount X-gal staining of adult ovaries showing oocytes from small (recruited primordial and primary follicles) to large (antral, preovulatory) follicular stages. In small oocytes with low levels of $\beta$-gal expression, X-gal staining appears as a small dot. In larger oocytes, a diffuse cytoplasmic staining is observed in addition to the dot. In ( $\left.\mathbf{b}^{\prime}-\mathbf{d}^{\prime}\right)$ panels, higher magnification of (b-d) panels is displayed. In the absence of imatinib treatment, low doses of irradiation lead to the disappearance of small oocytes (c'). In contrast, small oocytes are still detectable following irradiation of control females injected with imatinib (d'). Note the presence of oocytes of larger diameter in the mutant ovary treated with imatinib (arrows in $\mathrm{f}$ ). (g) Immunofluorescence analysis with anti- $\gamma \mathrm{H} 2 \mathrm{AX}$ and anti-p63 antibodies of ovarian sections from Omcg $1^{\text {ockO }}$ females treated with imatinib. Overlays with Hoechst staining (in grey) are presented. Arrows point to cells adopting thecal cell morphology. (Scale bars: $\mathbf{b}-\mathbf{g}, 200 \mu \mathrm{m} ; \mathbf{h}, 20 \mu \mathrm{m}$ )

despite early folliculogenesis arrest, Omcg $1^{\text {ocko }}$ mice exhibited several features of sexual cyclicity.

\section{Morphological and functional differentiation of ovarian} somatic cells from Omcg $1^{\text {ocKO }}$ females is associated with steroidogenic capacity. To further define the origin of estrogen secretion in mutant females, we examined the expression pattern of major components of the sex steroid biosynthesis pathways. (Figure $5 \mathrm{a}$ and Supplementary Figure S7). In control ovaries, Star was strongly expressed in corpora lutea and to some extent in the interstitial tissue and in theca cells (Figure 5a and Supplementary Figure S7). In mutant ovaries, Star was abundantly expressed in a large population of scattered cells mainly localized to the well-developed interstitial tissue (enlarged magnification in Figure 5a) and virtually absent from oocyte-depleted follicles. Cyp11a1 was highly expressed in corpora lutea, interstitial tissue and thecal cells as well as in mural granulosa cells of preovulatory follicles in controls. Interestingly, in mutant ovaries, Cyp11a1 was abundantly expressed in oocytedepleted follicles, in addition to the interstitial tissue. Furthermore, the androgen-converting enzyme Cyp19a1, whose expression was restricted to granulosa cells of preovulatory follicles in control ovaries, displayed a strong staining in oocyte-depleted follicles of mutant ovaries. Noteworthy, in situ studies for Lhcgr in mutant females revealed its expression in oocyte-depleted follicles in addition to the interstitial tissue. The observation that these structures 
a

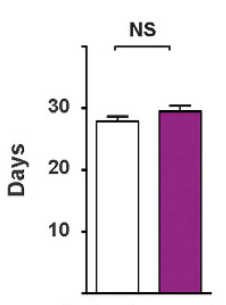

Puberty onset $\square$ control $\square$ mutant b

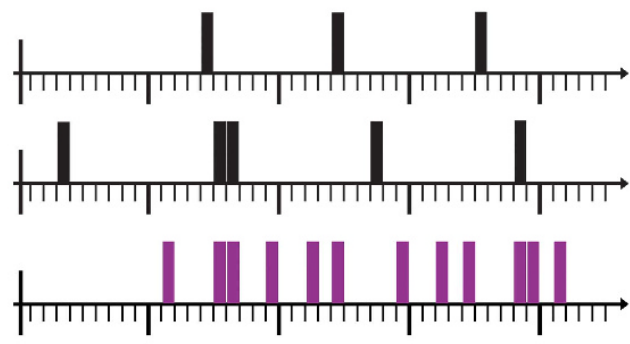

c
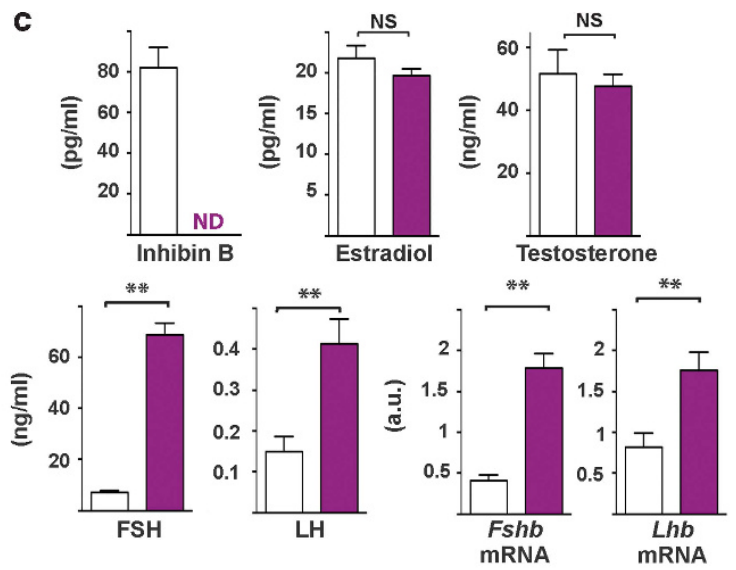

d

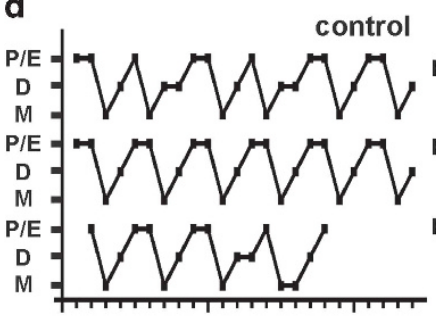

days

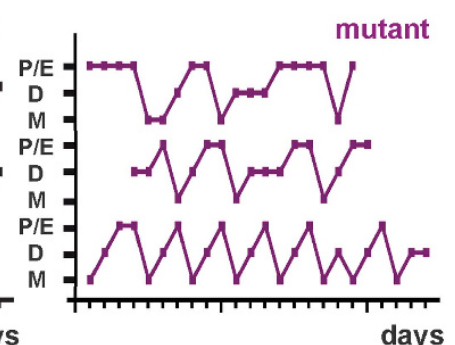

e

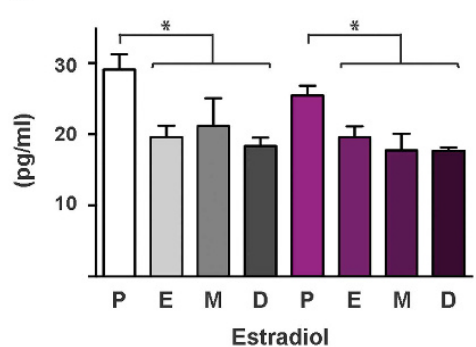

f

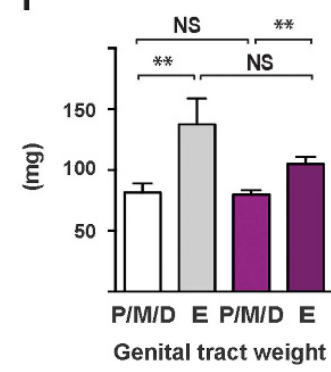

Figure 4 Normal puberty onset and estrous cyclicity in Omcg1 ${ }^{\text {ockO }}$ females. (a) Puberty onset as assessed by vaginal opening. (b) Omcg $1^{\text {ockO }}$ and control mice $(n=5$ and 2 females, respectively) were continuously mated with males over a 40-day period, and vaginal plugs were recorded every morning. Control females were mated with vasectomized males while Omcg $1^{\text {ocKO }}$ females were mated with either vasectomized (two females) or fertile (three females) males. Diagrams illustrate representative profiles of plugs in two control (black) and mutant (purple) females. Vaginal plugs were detected in mutant females indicating that sexual receptivity is maintained. Mean plugs intervals were of $5.33 \pm 0.97$ and $11.2 \pm 0.2$ days in mutant and control females, respectively (consecutive plugs were not taken into account). In mutant females, the shorter plug intervals result from the absence of corpora lutea and pseudo-pregnancy. (c) Serum levels of inhibin B, estradiol, testosterone, FSH and LH and quantitative RT-PCR studies of the relative mRNA levels of $F s h b$ and $L h b$ in pituitaries from control and mutant mice (ND: not detectable). (d) Diagrams representing the estrous cycles monitored daily over 24 days (P/E: proestrus/estrus; D: diestrus; M: metestrus). (e) Serum estradiol levels at different stages of the estrous cycle. (f) Genital tract weights at estrus versus the other stages of the cycle. The data are expressed as mean \pm S.E.M. of $n \geq 7$ mice (NS: not significant, $P>0.05 ;{ }^{*} P<0.05 ;{ }^{* *} P<0.01$ )

expressed Lhcgr, Cyp19a1 and Cyp11a1, which are normally found in preovulatory and luteinizing follicles, and not the luteinizing follicle marker Star indicate that they acquired features of pre-ovulatory follicles. Fshr was detected by realtime RT-PCR in mutant ovaries (Figure 5b), suggesting that FSH signaling pathway could be functional in these mice, probably in oocyte-depleted follicles. In line with the dramatic elevation of serum FSH and LH levels, which are key regulators of follicle differentiation, intra-ovarian content of Cyp11a1, Cyp19a1 and Lhcgr transcripts were significantly increased in mutant females as compared with controls (Figure 5b). Gene expression of other components of the steroidogenesis pathway known to be regulated by $\mathrm{LH}$, such as Cyp 17a 1 and $H s d 3 \beta$ were also upregulated (by $\sim$ twofold) (Figure 5b). Altogether, these findings suggest that mutant ovaries are endowed with fully developed steroidogenesis machinery allowing the production of estrogens.

\section{Discussion}

Relatively little is known about oocyte death and its regulation in the early phase of follicle growth. In this study, we identify OMCG1 as a critical regulator of oocyte genome integrity. We report that oocyte-specific deletion of Omcg1 leads to oocyte death in early growing follicles. Consequently, Omcg $1^{\text {ocKO }}$ mice show premature arrest of folliculogenesis and sterility. Factors processing pre-mRNA such as OMCG1 participate in the maintenance of genomic stability by preventing the formation of RNA-DNA hybrids (R-loops) during transcription. $^{23,24}$ In Omcg1-deficient cycling cells, formation of R-loops leads to replication forks collapse ${ }^{8}$ or mitotic catastrophe ${ }^{9}$ that in turn trigger a rapid cell death response. In contrast, no genomic instability was observed in noncycling Omcg1-deficient somatic cells. ${ }^{8}$ It is thus paradoxical that Omcg1 deficiency in prophase I-arrested oocytes provoked numerous DSB and caused rapid oocyte elimination. Oocyte entry in the growing phase is characterized by a burst of transcriptional activity required for the accumulation of maternal products. Because R-loops are able to block the progression of elongating RNA polymerase, ${ }^{25}$ DSB observed in Omcg1-deficient oocytes are likely to arise in highly transcribed loci following topological constraints consecutive to transcriptional conflicts or prolonged exposure of unstable single-stranded DNA at transcription bubbles. Interestingly, we observed reduced transcriptional activity in mutant oocytes. Whether this is a direct consequence of 
a
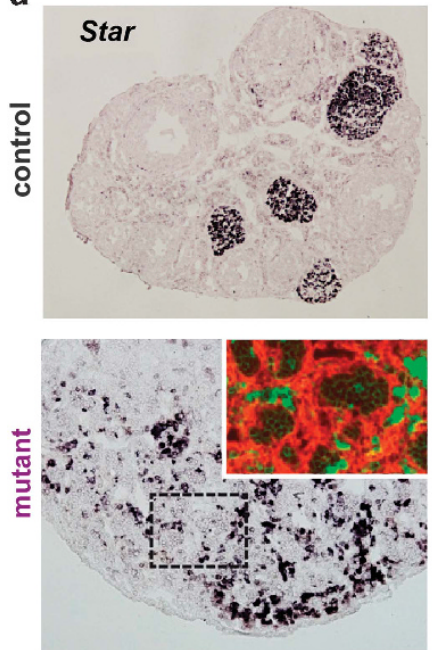
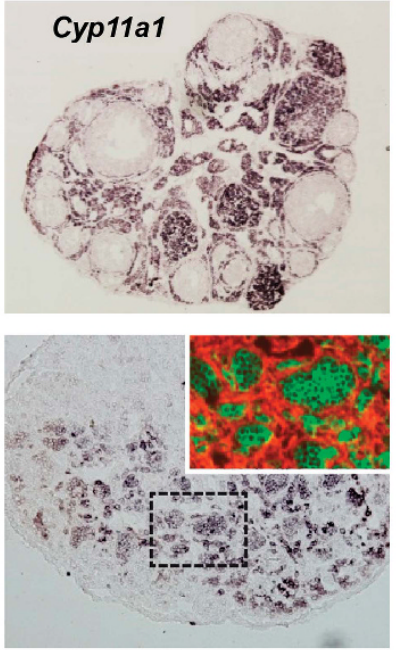

b
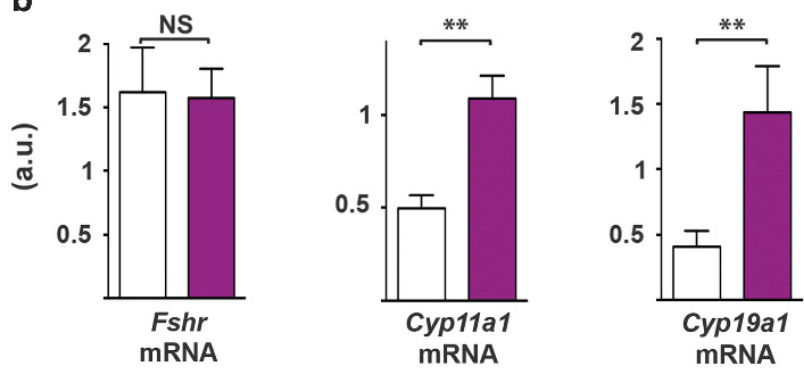
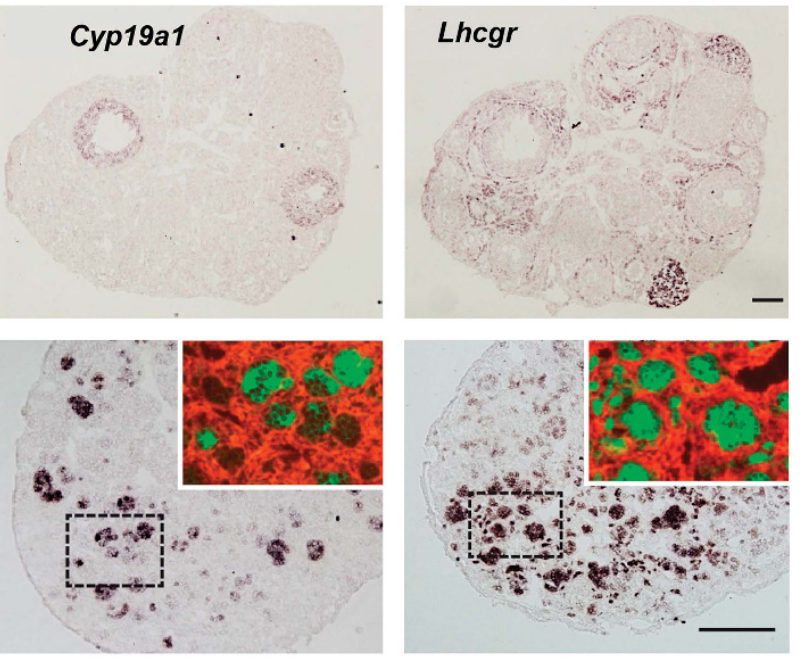

Figure 5 Expression patterns of major markers of the sex steroid biosynthesis pathway. (a) In situ hybridization for Star, Cyp11a1, Cyp19a1 and Lhcgr in control and mutant adult ovaries. Insets are higher magnification showing merged in situ hybridization staining (purple color digitally converted into green) and fibronectin immunolabeling (red). Strong staining is observed in oocyte-depleted follicles except for Star. Star, Cyp11a1 and Lhcgr are strongly expressed in the interstitial tissue, which is positive for fibronectin staining. (Scale bar: $200 \mu \mathrm{m}$ ). (b) Quantitative RT-PCR studies of Fshr, Cyp11a1, Cyp19a1, Lhcgr, Cyp17a1 and Hsd3b mRNA levels of in adult control (white) and mutant (purple) ovaries. The data are expressed as mean \pm S.E.M. of $n \geq 10$ mice (NS: not significant, $P>0.05 ;{ }^{* \star} P<0.01 ;{ }^{* * \star *} P<0.001$ )

R-loops formation or caused by activation of DNA damage response pathway is not known yet. Reduced transcriptional activity in early growing oocytes has been previously reported following inactivation of $\mathrm{Tbp} 2^{20}$ and $\mathrm{Hdac} 1 / 2{ }^{26}$ In both cases, follicles up to the antral stage were observed suggesting that reduced transcription per se is not responsible for the loss of primary follicle oocytes in Omcg $1^{\text {ocKO }}$ ovaries.

Rather, Omcg1-deficient oocyte elimination appeared to be caused by loss of DNA integrity and subsequent TAp63dependent oocyte death. Oocytes from primordial follicles are extremely sensitive to irradiation or genotoxins, and TAp63 has been shown to play a key role in the elimination of damaged oocytes in early postnatal ovaries. ${ }^{14,15,27}$ Much less attention has been paid to ovaries after puberty and at other follicular stages. Our study extends the role of TAp63 in oocyte quality control to primary follicles of adult ovaries. The nature of Omcg $1^{\text {ocKO }}$ model ensures that the primary cause of oocyte death originates from the oocyte itself, a situation that cannot be attained using whole-body exposure to genotoxic agents. According to current models, DNA damages trigger the phosphorylation of TAp63 by c-Abl and Chk2 kinases. ${ }^{16,28,29}$ We observed that pharmacological inhibition of C-Abl prevented elimination of damaged oocytes in Omcg $1^{\text {ockO }}$ ovaries, thus allowing oocyte growth and follicle differentiation to progress despite the presence of numerous $\gamma \mathrm{H} 2 \mathrm{AX}$ foci in the oocyte nucleus. Consistent with the inhibition of its phosphorylation, TAp63 levels remained high in damaged oocytes treated with imatinib. Participation of c-Abl/TAp63 pathway to physiological oocyte death in preantral stages has not been documented so far. In that respect, it would be interesting to analyze early steps of folliculogenesis in adult TAp63-deficient ovary.

The development of the Omcg $1^{\text {ocKO }}$ model provided us with the opportunity to investigate the fate of the ovarian somatic component following oocyte loss at the onset of folliculogenesis. Interestingly, follicular cells survived in the absence of the oocyte, lost their characteristics of early growing follicles (loss of AMH expression) and acquired pre-ovulatory follicle features (Cyp19a1 expression). Evidence from a number of germ cell depletion models suggests that the fate of companion somatic cells is influenced by the stage at which the oocyte is lost. ${ }^{30-34}$ This hypothesis is further emphasized by the present study, because in Omcg $1^{\text {ocKO }}$ mice, the loss of the oocyte at the primary follicle stage is not accompanied by the terminal differentiation of granulosa cells into luteal cells, at the difference of $\mathrm{Gdf9}^{-/-}$females. ${ }^{31,32}$ In the absence of Gdf9, follicular growth is blocked at the primary stage but the oocyte continues to grow before its elimination. The timing of oocyte loss may therefore account for the observed differences in granulosa cell fate between these two models. 
Importantly, the profound remodeling of the somatic compartment in Omcg $1^{\text {ocKO }}$ mice was accompanied by sex steroid production. In situ analysis of the steroidogenesis machinery supports the idea that Omcg $1^{\text {ocKO }}$ ovaries have gained the capacity to produce estradiol. Similar to the twocell compartment scheme between thecal and granulosa cells in normal ovaries, there would be cooperation between cells from the interstitial tissue and oocyte-depleted follicles for the production of this hormone (Figure 6). We speculate that the production of sex steroids in mutant females is boosted by high levels of gonadotropins resulting from the drop in inhibin $B$ levels (for review, Stocco ${ }^{35}$ ). In addition to being observed in other rodent models of oocyte depletion, ${ }^{36,37}$ similar hormonal changes can be found in women at the time of perimenopause and in cases of aberrant depletion of follicles such as those found in patients with Turner syndrome ${ }^{38}$ or treated by radio- and chemotherapy. ${ }^{39,40}$ In these different situations, it is interesting to note that despite marked folliculogenesis alteration and disrupted endocrine balance, estradiol circulating levels can be found normal, at least for a while. One proposed explanation was that measurable estradiol levels could arise from adrenal androgens. However, an ovarian origin should also be reconsidered in view of the present study showing that estradiol production can be ensured by the ovary even in the case of $\mathrm{POI}$ and sterility. It is tempting to propose that ovarian estrogen production could be, to some extent, under homeostatic control involving feedback loops from the ovary through Inhibin production and the hypothalamo-pituitary system through gonadotropin secretion. The existence of such a regulatory mechanism of estradiol production may be an adaptive response to maintain estradiol production when follicular content is low. Indeed, low estradiol levels may lead to various pathophysiological processes, including cancers and cardiovascular diseases. ${ }^{41}$ Detailed studies on other models of physiological or induced ovarian senescence should give further insights into this regulation.

In the present study, we made the remarkable discovery that mutant females exhibited normal onset of puberty and sexual receptivity (Figure 6). Furthermore, mutant females exhibited sexual cyclicity. These important observations suggest that ovarian steroidogenic activity fluctuates in mutant females despite early folliculogenesis arrest and lack of ovulation. There is some evidence that estrus cyclicity is under the control of internal clocks within the hypothalamopituitary-gonad axis (for review, Sellix et $a^{42}$ ). Although the underlying mechanisms have still to be uncovered in Omcg $1^{\text {ockO }}$ mice, our observations raise the question of the existence of such clocks in the ovary. It would be of interest to determine whether circadian oscillators could dictate the maintenance of estrous-related changes.

In conclusion, our findings uncover the key role of OMCG1dependent pre-mRNA processing in the maintenance of genome integrity in female germ cells and establish the role of TAp63 in oocyte death in early growing follicles. Moreover, our study is the first, to our knowledge, to report sexual receptivity and cyclicity in a model of POI. It therefore opposes, at least in the context of ovarian insufficiency, the current dogma whereby reproductive cyclicity is tightly driven by folliculogenesis and luteal differentiation. Our study further questions about the role of the oocyte in the acquisition of estrogenic ability and cyclic functioning of the ovary. Detailed analyses on other animal models of $\mathrm{POI}$ should bring further insights into the dramatic ovarian plasticity and endocrine capacity.

\section{Materials and Methods}

Mice. Control and $\mathrm{Omcg}{ }^{\text {ockO }}$ females were obtained by crossing mice harboring Omcg $1^{\text {flox }}\left(\right.$ Zfp830 $\left.^{\text {tm2.1Cota }}\right)$ and Omcg $1^{\text {del }}\left(\right.$ Zfp830 $\left.^{\text {tm2.2Cota }}\right){ }^{8}$ ZP3-Cre ${ }^{\text {tg }}$ $(\mathrm{Tg}(\mathrm{Zp} 3-\mathrm{cre}) \mathrm{Knw})^{11}$ and Rosa26R (Gt(ROSA)26Sor $\left.{ }^{\text {tm } 1 \text { Sor }}\right)^{12}$ alleles. Omcg $1^{\text {ocKO }}$ females were systematically compared with control littermates. PCR amplification with primers 1 (5'-GCCATAACAGGAAGTGACGCT), 2 (5'-GGTGTTACACA GTGCGCAGCT) and 3 (5'-AGCGCCAACCCTTGGAGTTTA) allowed to discriminate Omcg1 alleles: wild type (238 bp, primers 1 and 2), flox ( $326 \mathrm{bp}$, primers 1 and 2) and del (495 bp, primers 1 and 3), respectively. Tap63- (Trp63 $3^{\text {tm2Fm }}$ and $p 63^{-}\left({\left.\text {Trp } 63^{\text {tm1Brd }}\right)}\right.$ mice have been previously described. ${ }^{14,43}$ Experiments on mice were conducted according to the French and European regulations on care and protection of the Laboratory Animals (EC Directive 86/609, French Law 2001-486 issued on June 6, 2001) and the NIH Animal Welfare (Insurance \#A5476-01 issued on 02/07/2007).

Puberty, fertility assessment and estrous cycle monitoring. After weaning at 3 weeks post-natal, control and $O \mathrm{mcg} 1^{\circ \mathrm{ocKO}}$ females were monitored daily for vaginal opening to assess puberty onset. Vaginal cells from females aged 41-63 days were collected by daily saline wash and analyzed after May-GrünwaldGiemsa R (RAL Diagnostics, Martillac, France) staining. Stages of the estrous cycle were characterized by predominant cornified epithelial cells, predominant nucleated cells, both cornified and leukocytes and predominant leukocytes for estrus, proestrus, metestrus and diestrus stages, respectively. Fertility was assessed by housing control or mutant adult (2 months) females with a wild-type male. Cages were inspected twice a week and the number of pups recorded. Pups were kept with the mother for 2-3 weeks.

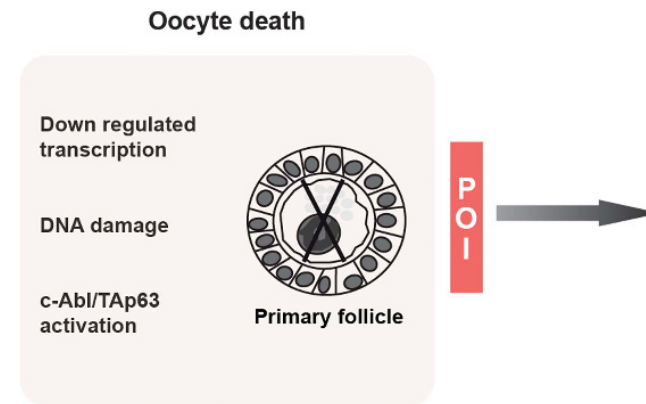

\section{Ovarian remodeling}

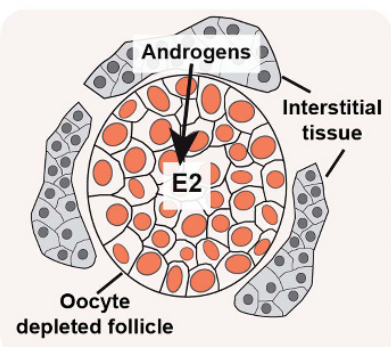

Sexual cyclicity

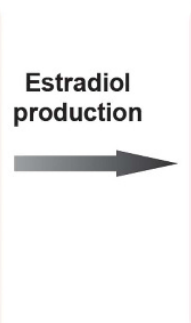

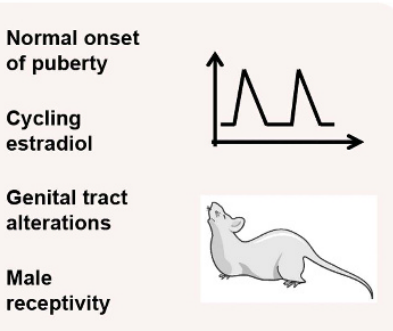

Figure 6 Summary of the reproductive features of Omcg $1^{\text {ocko }}$ females. Omcg $1^{\text {ocko }}$ females exhibited oocyte death at the primary follicle stage leading to folliculogenesis arrest and premature ovarian insufficiency (POI). Remodeling of the ovarian somatic compartment allows the production of estradiol (E2) that would occur along a two-cell compartment scheme similar to what is found between theca cells and granulosa cells in preovulatory follicles. Despite the absence of terminal follicular growth and luteal differentiation, Omcg ${ }^{10 \mathrm{cko}}$ females displayed features of sexual cyclicity 
Irradiation and imatinib treatment. Imatinib methylsufate (also known as Gleevec, $30 \mathrm{mg} / \mathrm{kg}$ of body weight, (VWR International, Fontenay-sous-Bois, France)) was injected intraperitonally twice a day for 2 days. At $24 \mathrm{~h}$ after the first injection, some treated and untreated control mice were exposed to a dose of $0.5 \mathrm{~Gy}$ at a rate of $1.68 \mathrm{~Gy} / \mathrm{min}$ using an IBL 637137 Cesium irradiator (CIS Bio International, Gif sur Yvette, France).

Histology, immuno- and X-gal staining. Genital tracts (containing the ovary, the oviduct and the adjacent uterus) from adult females aged 2 months were collected and incubated in 4\% paraformaldehyde (in PBS). The ovary was dissected out and processed for paraffin embedding or frozen sections as previously described. ${ }^{44}$ Periodic Acid and Schiff staining was carried out on $4-\mu \mathrm{m}$ paraffin sections. For histomorphometric analysis, serial ovarian sections were photographed and follicles were counted in every fifth sections using ImageJ software and cell counter plugin. Only follicles containing a healthy oocyte with a clearly visible nucleus were scored. The number of follicles per ovary was considered as the cumulative count. For immunochemistry, antigens were retrieved by boiling slides for $40 \mathrm{~min}$ in antigen unmasking solution (Vector ref H3300). Sections were then incubated in blocking solution (10\% horse serum, $10 \%$ goat serum, $10 \%$ fetal calf serum, $0.3 \%$ Triton X-100 in TBS-T $(50 \mathrm{mM}$ Tris, $150 \mathrm{mM} \mathrm{NaCl}, 0.05 \%$ Tween buffer)) for $20 \mathrm{~min}$ at room temperature. Incubation with primary antibodies was performed in the blocking solution at $4{ }^{\circ} \mathrm{C}$ overnight. See Supplementary Table $\mathrm{S} 1$ for lists of antibodies used in this study. Whole ovaries were fixed for $1 \mathrm{~h}$ at $4{ }^{\circ} \mathrm{C}$ in $4 \%$ paraformaldehyde-PBS containing $2 \mathrm{mM}$ $\mathrm{MgCl}$. Samples were rinsed and incubated at $32{ }^{\circ} \mathrm{C}$ in $\mathrm{X}$-Gal staining solution

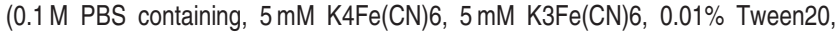
$2 \mathrm{mM} \mathrm{MgCl} 2,0.01 \%$ Nodinet P- $40,0.02 \%$ sodium deoxycholate and $4 \mathrm{mg} / \mathrm{ml}$ of X-gal (Invitrogen, La Jolla, CA, USA)). Imaging was performed using a Axiozoom (Zeiss, Marly le Roi, France) equipped with an AxioCam HRc (Zeiss), an automated whole slide imaging MiraxScan device (Carl Zeiss microlmaging, Marly le Roi, France) or an inverted microscope Zeiss Axiovert $200 \mathrm{M}$ with a Zeiss ApoTome system.

Histoenzymology: $3 \beta$-hydroxysteroid dehydrogenase (3 $\beta$-HSD) activity. $3 \beta$-HSD activity was revealed by deposits of formazan in delipidized and rehydrated sections incubated with $5 \beta$-androstan- $\beta$-ol-17one (3 $\beta$-etiocholanolone; Sigma, Saint-Quentin Fallavier, France) as substrate in the presence of nitro blue tetrazolium and NAD as previously described. ${ }^{45}$

In situ hybridization. Sense and antisense probes, labeled with digoxigenin11-UTP (Roche Diagnostics GmbH, Meylan, France), were synthesized using T7 and SP6 RNA polymerases from plasmid vectors containing DNA fragments of Cyp11, Star, Cyp17a1, Inha and Amh or from PCR products amplified from mouse ovary cDNA for Lhcgr, Inhba and Cyp19a1. Probes used in this study are listed on Supplementary Table 2. In situ hybridization was performed on frozen tissue sections as previously described. ${ }^{44}$ In some experiments, identification of ovarian structures in mutant females (interstitial tissue, oocyte-depleted follicles) was performed by immunostaining of fibronectin on in situ hybridization sections.

Terminal deoxynucleotidyltransferase-mediated deoxyuridine $5^{\prime}$-triphosphate-fluorescein nick end labeling (TUNEL). Detection of dying cells was performed on sections previously treated for AMH in situ hybridization using the in situ cell death detection kit, fluorescein (Roche, Boulogne-Billancourt, France). After PBS washing, sections were incubated $1 \mathrm{~h}$ at room temperature with the TUNEL reaction mixture containing terminal transferase to label free $3^{\prime}$-hydroxy ends of genomic DNA with fluorescein-labeled deoxy-UTP.

Hormone level assays. Blood was drawn from adult females by retro-orbital puncture between 4.30 and $6.00 \mathrm{pm}$ and collected in plastic centrifuge tubes. After centrifugation for $10 \mathrm{~min}$ at $8000 \mathrm{~g}$ at $4{ }^{\circ} \mathrm{C}$, sera were stored at $-20^{\circ} \mathrm{C}$ until analysis. Stages of the estrous cycle were determined by vaginal smear analysis on the morning of the day of blood sample collection and the days before. Most mice were bled only once. When several bleedings were performed on the same mice, a resting period of at least 15 days was observed. Hormone levels were measured by using commercially available RIA (for LH and estradiol) or ELISA (for FSH and inhibin B) kits (Beckman Coulter (Nyon, Switzerland) for estradiol and inhibin B, ImmunoDiagnosticsSystems (Paris, France) for LH and FSH). Testosterone was extracted from the serum and assayed by RIA as previously described. $^{46}$
Reverse-transcription and real-time PCR. Reverse transcription was carried out with $250 \mathrm{ng}$ of total RNA recovered from ovaries of mice aged 2 months, $400 \mathrm{ng}$ oligo-dT primers (Qiagen, Courtaboeuf, France) and Superscript II reverse transcriptase (Invitrogen, Cergy Pontoise, France). Real-time RT-PCR was performed with the LightCycler 480 instrument (Roche Diagnostics, Mannheim, Germany) using the LightCycler 480 SYBR Green I Master mix according to the manufacturer's protocol, as described in. ${ }^{47}$ Primers for Star, Cyp11a1, Cyp19a1 and Lhcgr are listed in Supplementary Table 3. All samples were run in quadruplicate reactions (duplicate of two dilutions). Quantification of gene expression was performed using the Relative Quantification Software (Roche Diagnostics), and data were expressed as a ratio of target gene to the reference gene hypoxanthine phosphoribosyltransferase, Hprt.

Statistical analysis. Data collected from at least three different animals were analyzed using using Prism 6.0 (GraphPad software, Inc, La Jolla, CA, USA) and were expressed as the mean \pm S.E.M. Statistical significance was determined by Mann-Whitney test or by two-way ANOVA in conjunction with a post hoc multiple comparison test (Dunnett's test) if necessary. A $P$-value of less than 0.05 was considered significant.

\section{Conflict of Interest}

The authors declare no conflict of interest.

Acknowledgements. We thank C Rachez, L Tora and ME Torres-Padilla for antibodies against Polll and mTBP2, JY Picard for anti-AMH antibody, F McKeon for TAp63 KO mice, S. Coqueran and A. Stedman for their help for real-time PCR, F Bourgade for his help in blood samples collection, V Rouiller-Fabre, D Moisan and $C$ Denoyelle for their help in hormone assays. We are grateful to $\mathrm{P}$ Monget for helpful discussion and to J Artus and G Livera for critical reading of the manuscript. This work was supported by the Centre National de la Recherche Scientifique, the Institut Pasteur, the University Paris Diderot and the Agence Nationale de la Recherche (contract \# ANR-2010-BLAN-1232-01 EARLYFOLL and ANR-10-LABX73-01 REVIVE). This work is dedicated to the memory of Charles Babinet.

1. Burger HG, Hale GE, Dennerstein L, Robertson DM. Cycle and hormone changes during perimenopause. Menopause 2008; 15: 603-612.

2. Shelling AN. Premature ovarian failure. Reproduction 2010; 140: 633-641.

3. Moore GP, Lintern-Moore S. Transcription of the mouse oocyte genome. Biol Reprod 1978; 18: 865-870.

4. Eppig JJ. Oocyte control of ovarian follicular development and function in mammals. Reproduction 2001; 122: 829-838.

5. Song JL, Wessel GM. How to make an egg: transcriptional regulation in oocytes. Differentiation 2005; 73: 1-17.

6. Bessonov S, Anokhina M, Will CL, Urlaub H, Lührmann R. Isolation of an active step I spliceosome and composition of its RNP core. Nature 2008; 452: 846-850.

7. Kuraoka I, Ito S, Wada T, Hayashida M, Lee L, Saijo M et al. Isolation of XAB2 complex involved in pre-mRNA splicing, transcription, and transcription-coupled repair. J Biol Chem 2008; 283: 940-950.

8. Houlard M, Artus J, Léguillier T, Vandormael-Pournin S, Cohen-Tannoudji M. DNA-RNA hybrids contribute to the replication dependent genomic instability induced by Omcg1 deficiency. Cell Cycle 2011; 10: 108-117.

9. Léguillier T, Vandormael-Pournin S, Artus J, Houlard M, Picard C, Bernex F et al. Omcg1 is critically required for mitosis in rapidly dividing mouse intestinal progenitors and embryonic stem cells. Biol Open 2012; 1: 648-657.

10. Artus J, Vandormael-Pournin S, Frödin M, Nacerddine K, Babinet C, Cohen-Tannoudji M et al. Impaired mitotic progression and preimplantation lethality in mice lacking OMCG1, a new evolutionarily conserved nuclear protein. Mol Cell Biol 2005; 25: 6289-6302.

11. de Vries WN, Binns LT, Fancher KS, Dean J, Moore R, Kemler R et al. Expression of Cre recombinase in mouse oocytes: a means to study maternal effect genes. Genesis 2000; 26: $110-112$.

12. Soriano P. Generalized lacZ expression with the ROSA26 Cre reporter strain. Nat Genet 1999; 21: 70-71.

13. Devine PJ, Payne CM, McCuskey MK, Hoyer PB. Ultrastructural evaluation of oocytes during atresia in rat ovarian follicles. Biol Reprod 2000; 63: 1245-1252.

14. Suh E-K, Yang A, Kettenbach A, Bamberger $\mathrm{C}$, Michaelis AH, Zhu Z et al. p63 protects the female germ line during meiotic arrest. Nature 2006; 444: 624-628.

15. Livera G, Petre-Lazar B, Guerquin MJ, Trautmann E, Coffigny H, Habert R et al. p63 null mutation protects mouse oocytes from radio-induced apoptosis. Reproduction 2008; 135: 3-12. 
16. Gonfloni S, Di Tella L, Caldarola S, Cannata SM, Klinger FG, Di Bartolomeo C et al. Inhibition of the c-Abl-TAp63 pathway protects mouse oocytes from chemotherapy-induced death. Nat Med 2009; 15: 1179-1185.

17. Kurita T, Cunha GR, Robboy SJ, Mills AA, Medina RT. Differential expression of p63 isoforms in female reproductive organs. Mech Dev 2005; 122: 1043-1055.

18. Kerr JB, Hutt KJ, Michalak EM, Cook M, Vandenberg CJ, Liew SH et al. DNA damageinduced primordial follicle oocyte apoptosis and loss of fertility require TAp63-mediated induction of Puma and Noxa. Mol Cell 2012; 48: 343-352.

19. Deutsch GB, Zielonka EM, Coutandin D, Weber TA, Schäfer B, Hannewald J et al. DNA damage in oocytes induces a switch of the quality control factor TAp63 $\alpha$ from dimer to tetramer. Cell 2011; 144: 566-576.

20. Gazdag E, Santenard A, Ziegler-Birling C, Altobelli G, Poch O, Tora L et al. TBP2 is essential for germ cell development by regulating transcription and chromatin condensation in the oocyte. Genes Dev 2009; 23: 2210-2223.

21. Lanuza GM, Groome NP, Barañao JL, Campo S. Dimeric inhibin A and B production are differentially regulated by hormones and local factors in rat granulosa cells. Endocrinology 1999; 140: 2549-2554

22. Nelson JF, Felicio LS, Osterburg HH, Finch AJ. Altered profiles of estradiol and progesterone associated with prolonged estrous cycles and persistent vaginal cornification in aging C57BL/6J mice. Biol Reprod 1981; 24: 784-794.

23. Paulsen RD, Soni DV, Wollman R, Hahn AT, Yee MC, Guan A et al. A genome-wide sirna screen reveals diverse cellular processes and pathways that mediate genome stability. Mo Cell 2009; 35: 228-239.

24. Li X, Manley JL. Inactivation of the SR protein splicing factor ASF/SF2 results in genomic instability. Cell 2005; 122: 365-378.

25. Aguilera A, García-Muse T. R loops: from transcription byproducts to threats to genome stability. Mol Cell 2012; 46: 115-124.

26. Ma P, Pan H, Montgomery RL, Olson EN, Schultz RM. Compensatory functions of histone deacetylase 1 (HDAC1) and HDAC2 regulate transcription and apoptosis during mouse oocyte development. Proc Natl Acad Sci USA 2012; 109: E481-E489.

27. Morita Y, Perez GI, Paris F, Miranda SR, Ehleiter D, Haimovitz-Friedman A et al. Oocyte apoptosis is suppressed by disruption of the acid sphingomyelinase gene or by sphingosine-1-phosphate therapy. Nat Med 2000; 6: 1109-1114.

28. Maiani E, Di Bartolomeo C, Klinger FG, Cannata SM, Bernardini S, Chateauvieux S et al. Reply to: Cisplatin-induced primordial follicle oocyte killing and loss of fertility are no prevented by imatinib. Nat Med 2012; 18: 1172-1174.

29. Bolcun-Filas E, Rinaldi VD, White ME, Schimenti JC. Reversal of female infertility by Chk2 ablation reveals the oocyte DNA damage checkpoint pathway. Science 2014; 343 533-536.

30. Guigon CJ, Magre S. Contribution of germ cells to the differentiation and maturation of the ovary: insights from models of germ cell depletion. Biol Reprod 2006; 74: 450-458.

31. Dong J, Vuojolainen K, Jaatinen R, Ketola I, Aaltonen J, Lehtonen E et al. Growth differentiation factor-9 is required during early ovarian folliculogenesis. Nature 1996; $\mathbf{3 8 3}$ : $531-535$.
32. Elvin JA, Yan C, Wang P, Nishimori K, Matzuk MM. Molecular characterization of the follicle defects in the growth differentiation factor 9-deficient ovary. Mol Endocrinol 1999; 13: 1018-1034.

33. el-Fouly MA, Cook B, Nekola M, Nalbandov AV. Role of the ovum in follicular luteinization. Endocrinology 1970; 87: 286-293.

34. Nekola MV, Nalbandov AV. Morphological changes of rat follicular cells as influenced by oocytes. Biol Reprod 1971; 4: 154-160.

35. Stocco C. Aromatase expression in the ovary: hormonal and molecular regulation. Steroids 2008; 73: 473-487.

36. Guigon CJ, Coudouel N, Mazaud-Guittot S, Forest MG, Magre S. Follicular cells acquire sertoli cell characteristics after oocyte loss. Endocrinology 2005; 146: 2992-3004.

37. McNeilly JR, Watson EA, White YA, Murray AA, Spears N, McNeilly AS et al. Decreased oocyte DAZL expression in mice results in increased litter size by modulating folliclestimulating hormone-induced follicular growth. Biol Reprod 2011; 85: 584-593.

38. Hagen CP, Main KM, Kjaergaard S, Juul A. FSH, LH, inhibin B and estradiol levels in Turner syndrome depend on age and karyotype: longitudinal study of 70 Turner girls with or without spontaneous puberty. Hum Reprod 2010; 25: 3134-3141.

39. Lutchman Singh K, Davies M, Chatterjee R. Fertility in female cancer survivors: pathophysiology, preservation and the role of ovarian reserve testing. Hum Reprod Update 2005; 11: 69-89.

40. Hale GE, Burger HG. Hormonal changes and biomarkers in late reproductive age, menopausal transition and menopause. Best Pract Res Clin Obstet Gynaecol 2009; 23: 7-23.

41. Burger HG. Physiological principles of endocrine replacement: estrogen. Horm Res 2001; 56(Suppl 1): 82-85.

42. Sellix MT, Yoshikawa T, Menaker M. A circadian egg timer gates ovulation. Curr Biol 2010; 20: R266-R267.

43. Mills A, Zheng B, Wang XJ, Vogel H, Roop DR, Bradley A et al. p63 is a p53 homologue required for limb and epidermal morphogenesis. Nature 1999; 398: 708-713.

44. Guigon CJ, Mazaud S, Forest MG, Brailly-Tabard S, Coudouel N, Magre S et al. Unaltered development of the initial follicular waves and normal pubertal onset in female rats after neonatal deletion of the follicular reserve. Endocrinology 2003; 144: 3651-3662.

45. Mazaud S, Guigon CJ, Lozach A, Coudouel N, Forest MG, Coffigny H et al. Establishment of the reproductive function and transient fertility of female rats lacking primordial follicle stock after fetal gamma-irradiation. Endocrinology 2002; 143: 4775-4787.

46. Habert R, Picon R. Testosterone, dihydrotestosterone and estradiol-17 beta levels in maternal and fetal plasma and in fetal testes in the rat. J Steroid Biochem 1984; 21: 193-198.

47. Magre S, Rebourcet D, Ishaq M, Wargnier R, Debard C, Meugnier E et al. Gender differences in transcriptional signature of developing rat testes and ovaries following embryonic exposure to 2,3,7,8-TCDD. PLoS One 2012; 7: e40306.

Supplementary Information accompanies this paper on Cell Death and Differentiation website (http://www.nature.com/cdd) 